\title{
Modals and Modal Epistemology
}

\author{
Jonathan Jenkins Ichikawa \\ University of British Columbia \\ ichikawa@gmail.com
}

4 April, 2015

To appear in Amy Kind and Peter Kung (eds.), Knowledge Through Imagination, Oxford University Press.

\begin{abstract}
I distinguish (§1) two projects in modal epistemology-one about how we come to know modal truths, and one about why we have the ability so to come to know. The latter, I suggest, $(\S \S 2-3)$ is amenable to an evolutionary treatment in terms of general capacities developed to evaluate quotidian modal claims. I compare (\$4) this approach to a recent suggestion in a similar spirit by Christopher Hill and Timothy Williamson, emphasizing counterfactual conditionals instead of quotidian modals; I argue that while there are some reasons to prefer the quotidian modals approach, there are none favoring the Hill/Williamson counterfactual approach. I conclude (§5) with a suggestion that the remaining questions both approaches leave unanswered ought not to be too troubling.
\end{abstract}

\section{Introduction}

There is a substantial contemporary literature engaging with questions about the epistemology of metaphysical modality; in its typical instances, it neglects the connections between metaphysical modals and their quotidian counterparts. This is, I think, a significant error. Claims of metaphysical modality are best understood as particular cases of modal claims generally; the epistemology of the former should be understood as continuous with that of the latter. Consequently, we face no need to posit anything like a sui generis faculty for metaphysical modality. Neither ought we, as Christopher Hill and Timothy Williamson have each recently suggested, understand knowledge of modality in terms of counterfactuals.

\section{§1. Why Questions in Modal Epistemology}

Modal epistemology concerns our epistemic access to facts about modality. In particular, modal epistemology typically concerns itself with questions about our knowledge (or justified beliefs, etc.) of claims about metaphysical possibility and metaphysical necessity. One obvious question about our epistemic access to facts about metaphysical possibility and necessity is this one:

(How) How do we come to know facts about metaphysical possibility and necessity? 
The How question is familiar in the relevant literature, as are various responses to it. According to one familiar response, we come to know propositions to be possible by conceiving of them, or by conceiving of them in a certain privileged sort of way. ${ }^{1}$ According to another familiar response, we use a faculty of rational intuition to come to know truths of modality. ${ }^{2}$ A different sort of response rejects the presupposition of the question, suggesting that the apparent ubiquity of knowledge of metaphysical modality is an illusion brought on by hubristic overconfidence. ${ }^{3}$

This How question about knowledge has close cousins, such as How do we come to have justified beliefs about metaphysical possibility and necessity? and How do we come to have reliable beliefs about metaphysical possibility and necessity? The sorts of responses mentioned above to the How question typically go along with corresponding answers to the How-Justified and How-Reliable questions in obvious ways; one might hold, for instance, that conceivability is appropriately and correctly trusted as a reliable guide to possibility, such that believing the conceivable possible is always justified, and, when things go rightly, knowledge. Different approaches to modal epistemology emphasize different of these questions. I'll focus on the knowledge version, although I don't think it should make much difference for present purposes.

What these How questions all have in common is that they are all questions about us. Who are we, exactly? This is to some degree an open question, but it's certainly meant to include at least us philosophers who have come to what we take to be a knowledgable consensus about various matters of metaphysical possibility and necessity. Many of us, for instance, apparently know, having read Kripke, that water is necessarily $\mathrm{H}_{2} \mathrm{O}$, and that it's possible for that meter stick in Paris to be longer than one meter. More mundanely, we seem to know such modal facts as that it was possible for Mitt Romney to have won the election over Barack Obama, but impossible for him to have identified the largest prime number. Maybe many non-philosophers have some or all of this knowledge too. The How questions ask, at least, how we philosophers know the modal truths in question.

The proper responses to the How questions, therefore, are beholden to psychological facts about us. If, for instance, as Cappelen (2012) argues at length, it turns out that as a matter of psychological fact, we don't use a faculty of intuition in coming to judge modal truths, then the answer to the How question that says we do is incorrect. Psychological questions about how philosophers come to judge philosophical matters are interesting ones, but, as is the case with most psychological questions, the relevant data are rather complex, and not particularly well-suited to discovery by traditional forms of philosophical methodology. It's not very easy in general to tell how we go about coming to believe and

\footnotetext{
${ }^{1}$ Eg. Yablo (1993). Cf. also Chalmers (2002).

${ }^{2}$ Eg. Bealer (2002), Sosa (2007), ch. 3.

${ }^{3}$ Eg., in a limited version, van Inwagen (1998). See also the view discussed in O'Leary-Hawthorne (1996), p. 185 .
} 
know what we do; the case of belief and knowledge about metaphysical modality does not seem to be exceptionally transparent.

The philosopher, therefore, who finds herself interested in the How question, might be well-advised, at least as a first step, to limit her focus to a slightly more modest question that abstracts away from some of the psychological complications of humanity.

(How Could) How could we come to know facts about metaphysical possibility and necessity?

The same set of responses are available here as before. (And so likewise with the 'How Could' counterparts for justification, reliability, etc.) The same questions would need to be answered about the various connections between, e.g., intuitions and modal facts, here as there; here, however, we set aside worries about the actual psychological implementation of the judgments in the wild. ${ }^{4}$

All of these questions, in the taxonomy I am about to suggest, are part of a single project in modal epistemology. Call this the 'How' project. The How project investigates how it is that we or various other people do or can come to have epistemic access to propositions about metaphysical modality.

The How question is not the only question one might be concerned to answer; and in some cases, it is not the most interesting one. We often want to know, in addition or even instead, why knowers are able to discern the relevant facts. To motivate this change in focus, consider the following story.

Suppose that we were someday to discover, in a distant solar system, a civilization whose members seemed to know quite a lot about King Ludwig II. They had, we will suppose, never travelled to Earth, or spoken to inhabitants of nineteenth-century Bavaria.

Nevertheless, when we finally do come to encounter them, they report various beliefs that are suggestive of an intimate knowledge of Ludwig's life; they tell of his childhood in Hohenschwangau, his obsession with Wagner, his elaborate castles, and the creation of the German Empire. This alien civilization at least appears to have quite a bit of knowledge about Ludwig; this would be a striking fact, calling out for explanation. Perhaps we would investigate their cognitive lives in an attempt to answer questions in the How project: how do they know so much about Ludwig? Correctly answering the How question might well resolve the mystery - if we were to discover, for instance, that they had an extremely powerful telescope that was focused on mid-1800s Europe, this would go quite a long way towards explaining what is mysterious about their knowledge of Ludwig.

\footnotetext{
${ }^{4}$ Compare Ichikawa and Jarvis (2012) p. 154, fn. 3: "[O]ur paper will focus primarily on the question of how we can have modal knowledge, rather than on the related question how we do come to have it. How we do have modal knowledge is as much a question of psychology as it is epistemology - we won't pretend to know from the armchair how people do know except to say that they are somehow sensitive to the method by which they can come to have it."
} 
But not all true answers to How questions would so resolve the mystery. Suppose that it came to light that the way our alien knowers come to beliefs about Ludwig is by swimming to the bottom of a particular deep well and meditating. Upon leaving the well, they find themselves with beliefs about Ludwig — beliefs that turned out overwhelmingly to be true. This discovery, though it would truly answer the How question, would not at all dispel the mystery of their access to Ludwig. That this answer is so obviously unsatisfactory indicates that the How question doesn't always get at the heart of what is of interest in epistemology.

One might of course worry that this discovery would not answer the How question, because reliable belief-formation isn't sufficient for knowing - perhaps the case as described is relevantly like Lehrer's (2000) Truetemp or BonJour's (1985) Norman. But even if we grant the internalist assumption, we needn't interpret the case as relevantly parallel. An important feature of Truetemp and Norman is that they have no independent reason to trust their inclinations. We can give my aliens such an independent reason without undermining the point they illustrate. We may, for instance, suppose that they are making use of a widely-calibrated well of clairvoyance: it delivers beliefs about a wide variety of things, many of which turn out upon independent investigation to be true. So they could rationally trust their well as reliable; there is still a deep mystery about cognitive access. This is why it is not sufficient or satisfying merely to argue for the presence of a reliable faculty. One might be convinced, on broadly transcendental grounds like those of Bealer (1992), that we must accept that our intuitions tend by and large to be true; that's certainly a good-making feature of intuitions, but it's not the end of the story by any means. A deeper explanation is needed.

Here is another example. Suppose that someone, or some group of people, have an apparent ability to tell, without aid of a scale, whenever some object weighs an even number of grams. It's not just that they have general super-human discriminatory abilities - I can't tell the difference by feel between $200 \mathrm{~g}$ and 202g, and neither can they - but they can always tell you whether, when rounded to the nearest number of grams, that number is even or odd. Even-grammed objects just feel a certain way to these subjects. These people, it seems, have an extraordinary ability that cries out for explanation. Suppose we investigate and find the particular neural mechanisms that underwrite their abilities. This would tell us how they know that this object is an even number of grams, but it would not satisfy our proper curiosity about their surprising ability. Answering the How question often yields only part of the story.

So it is with modal epistemology. If, as orthodoxy has it, we have epistemic access to facts about metaphysical possibility and necessity, this is an interesting fact that requires explanation. And answering a How question might not satisfy this requirement. Consider this answer to How: "Upon entertaining certain propositions, we experience conscious episodes with a particular sort of phenomenal character, which we recognize to be a reliable indicator of metaphysical necessity, and so conclude that the propositions are necessary. Thus do we come to knowledge of necessity." Even if this story were true, it would not provide any interestingly deep explanation for our capacity for modal knowledge. Saying only that the ability derives from a particular sort of rational capacity 
that allows us to distinguish the necessary and possible, even if true, does little more than does saying that our aliens meditate at the bottom of a well to learn about King Ludwig, or that our subjects use a particular bit of neural machinery, or its attendant phenomenology, to know whether an object has an even number of grams.

David Lewis provides an extreme example of a treatment of modal epistemology that is inadequate precisely for its neglect of the Why question:

"[I]f it is a necessary truth that so-and-so, then believing that so-and-so is an infallible method of being right. If what I believe is a necessary truth, then there is no possibility of being wrong. That is so whatever the subject matter of the necessary truth and no matter how it came to be believed." (Lewis 1986b, pp. 114-115)

And in fact, the situation here, with this answer to the How question for modal truths, is worse than in those analogies posited above. For we have independent access to facts about Ludwig and masses, and overwhelming reason to treat each as objective, mindindependent phenomena. This is less clear in the case of modality; if our best explanation of modal knowledge is such an unsatisfying answer to the How question, we are left with a deep mystery; we might avoid it if we gave up on the orthodoxy that we have access to modal truths, embracing skepticism, or embraced some sort of anti-realism about modality, closing the epistemic gap between truth and judgment. So failure to explain cognitive access could put pressure against the orthodoxy that we're achieving knowledge of objective facts.

Traditional philosophical concerns require more. We seek not merely answers to the How questions, but answers to Why questions as well.

(Why) Why do we have the ability to know facts about metaphysical possibility and necessity? ${ }^{6}$

Correspondingly, we want to know why it is that our clairvoyant aliens are able to know so much about King Ludwig, and why our odd subjects are able to tell whether an object weighs an even number of grams. For instance, if we learned that the subjects in question had been training all their lives at distinguishing objects weighing even numbers of grams, the mystery would be considerably lessened; although we'd still be surprised and impressed that they'd managed it so well, we can at least see a sketch of a story about how the ability came to be. ${ }^{\text {? }}$

\footnotetext{
${ }^{5}$ I owe the example to Schechter (2010), who uses it to make roughly the same point. See also O'LearyHawthorne (1996).

${ }^{6}$ Cf. the distinction between Schechter's (2010) distinction between the "operational question" and "etiological question" for the epistemology of logic; these correspond closely to my How and Why questions, respectively. My names are imperfect — one can ask a Why question via "how is it that we are able to know?"- but I hope that the intended contrast is clear.

${ }^{7}$ Of course, there can be unsatisfactory answers to the Why question, too- " they evolved a relevant mechanism," for instance, tells us very little by itself, but might truly answer the Why question. The point
}

Ichikawa 
Three points arise with respect to the relation between Why questions and How questions. First, although they're separate questions, they're not wholly independent. Certain answers to How questions place constraints on Why questions, and vice versa. A How answer, for instance, may tell what mechanism is used to come to knowledge; its corresponding Why answer, therefore, had better be able to explain why that mechanism, or a mechanism with its characteristic features, came to be. One might worry that certain answers to the How questions for modal epistemology might not be consistent with any plausible answers to Why questions.

Second, in at least some cases, the Why questions go a considerable distance towards resolving the relevant mysteries, even absent an answer to the How questions. If we learn that the subjects spent their childhoods trying to develop the capacity to detect odd-gramweighted objects, then, even absent a psychological story about how it is they actually do it, the fact that they manage it is not deeply mysterious in the way that discovering it with no explanation at all for how it came to be would be. (According to legend, chickensexers are notoriously skilled at distinguishing male from female chickens; it is surprising to learn that they do it by smell, but even before we know this answer to the How question, their ability is rendered rather unmysterious by the obvious answer to the Why question: they acquired this ability because they practiced it, along with the relevant positive and negative feedback.)

Third, Why questions may not always be pressing. It is very plausible that evolution provides a rather neat answer to the Why question about our ability to identify dangerous animals by sight. But if it should turn out - surprisingly - that as a matter of historical fact, our capacity to recognize dangerous animals arose by total coincidence, irrespective of natural selection, this wouldn't lead to great new mysteries about the epistemology of dangerous animals. ${ }^{8}$ (It might lead to mysteries about human development, but this is neither here nor there.) In some cases, it is enough to see that we have an ability, without regard to where it came from. What distinguishes cases where the Why question is pressing from those where it is not? I don't know how to give a general answer here, but the cases I presented above do suggest that the Why question is pressing at least sometimes. I also find it pressing in the case of modal epistemology. I suspect that this is so in part—but not wholly — because, unlike in the case of dangerous animals, it's unclear what independent check there is, either to corroborate our judgments of what is and is not possible, or even to confirm the thought that there is an objective fact about metaphysical possibility. We shall return to the question of to what degree we should find the Why question for modal epistemology pressing in $\S 3$.

In previous work, Benjamin Jarvis and I (Ichikawa \& Jarvis 2012, 2013) have developed a treatment of the How question for modal epistemology along broadly rationalist lines. My topic for this chapter is the Why question.

is that the Why question is an important one that often needs consideration, not that correct answers to it always resolve the relevant mysteries. Thanks to Derek Ball here.

${ }^{8}$ Thanks to Peter Kung for discussion here.

Ichikawa 


\section{§2. Metaphysical Modals and Quotidian Modals}

Evolutionary explanations are well-suited to Why questions. If a species developed in an environment where objects weighing an even number of grams are nutritious, but those weighing an odd number of grams are poisonous, we would not be surprised to discover that they'd developed a capacity for sensitivity to the difference. Are there prospects for such answers in the case of modal epistemology? Prima facie, one might think not: knowledge of metaphysical modality does not appear to confer any obvious survival or reproductive advantage in the environments in which our species developed.

But of course, evolutionary explanations for abilities needn't cite fitness advantages for those very abilities; if there are related abilities that would have carried fitness advantages, which would have carried the ability for knowledge of metaphysical modality as a side-effect, then the evolutionary strategy is promising. Here there is much more room for optimism. It is not difficult to think that there could have been a fitness advantage to knowledge of quotidian modal facts - the sorts of things we express with modal language in everyday nonphilosophical contexts - and that a capacity for recognitions of such quotidian modals would develop alongside a capacity for recognizing the more distinctively philosophically metaphysical modals that characterize the typical subject matter of modal epistemology.

This strategy will be pursued in $\S 3$. First, however, there is an important bit of stagesetting to do. For the strategy is promising only to the extent that claims of metaphysical modality are importantly similar to claims of quotidian modality. In this section, I argue that this is so.

It is widely recognized that the language of possibility is used in several importantly distinct ways. The first distinction standardly drawn in the literature is the distinction between epistemic and non-epistemic modals. ${ }^{9}$ These sentences can all be read in epistemic or nonepistemic ways:

$$
\text { It's possible that Renoir painted Beach at Sainte-Adresse. }
$$

John F. Kennedy might have survived his assassination attempt.

Roger Clemens must have used steroids.

If I'm matching painters to paintings, and don't know whether to leave open the possibility that Renoir painted Beach, I'd express an epistemic truth by (1). By contrast, if I'm attempting to deny Kripke's doctrine of the necessity of origin, (1) would

\footnotetext{
${ }^{9}$ Gendler \& Hawthorne (2002) p. 3, Bealer (2002) p. 77. We can also distinguish both these readings from deontic interpretations of modals, which I will not discuss in this paper. The focus of this paper is on, in Kratzer's (1981) terminology, modals with realistic modal bases - bases that always include the base world.
} 
constitute a metaphysical claim - if Kripke is right, a false one. ${ }^{10} \mathrm{I}^{\prime} 11$ utter (2) epistemically if I am raising a conspiracy theory on which Kennedy's death was faked; alternatively, I might take the death as given, and use (2) to convey the idea that Kennedy was unlucky that his attacker was successful. The natural reading for (3) is epistemicjust look at his performance late in his career, he must have used steroids - but it could be used to express the implausible claim that, as a matter of metaphysical necessity, Clemens used steroids.

But even setting aside epistemic readings, we have stronger and weaker notions of possibility and necessity that can come into play. All of these have true non-epistemic readings in some contexts, even though they'd be false if interpreted as claims about metaphysical modality.

No human can outrun a cheetah.

It's impossible for a prisoner to escape from Guantanamo Bay.

You can't win an election by promising tax hikes.

So it is common ground that utterances of modal claims such as (1)-(6) can have different truth conditions, depending on the conversational context. Sometimes, but not other times, they express claims of metaphysical possibility and necessity like those that characterize the subject matter for investigations into 'modal epistemology'. What accounts for this context-sensitivity?

One possible interpretation of these data would suggest that modal terms like 'possible', 'might', and 'can' are multiply ambiguous. On this suggestion, 'possible', for example, might be ambiguous between several distinct notions, including at least epistemic possibility and metaphysical possibility. This ambiguity thesis is implausible for many reasons. First, the sheer number of senses that need be distinguished should be daunting for anyone who wants to posit that the context-sensitivity of (1)-(6) is explained by ambiguity in the modal terms. Distinguishing metaphysical possibility and epistemic possibility is, of course, only a small first step; sentences like (4) suggest a need for something like 'physical possibility'; perhaps (6) demands 'political possibility', etc. If 'possibility' is ambiguous in this way, then each sense would have to be independently learned; this is obviously not the case. ${ }^{11}$ It is also a surprising and unexplained fact, given the ambiguity thesis, that the various meanings of the modal terms are related in

\footnotetext{
${ }^{10}$ E.g. Kripke (1980), pp. 113-15.

${ }^{11}$ The linguistic meaning is the same in each case; this doesn't imply, of course, that one mightn't need to learn to identify particular modal bases independently. An ability to recognize 'physical possibility' doesn't guarantee competence with 'political possibility' (or metaphysical possibility); one might be linguistically competent with 'possible' without knowing, in a given context, which worlds are relevant. (Compare linguistic competence with 'everyone', which does not guarantee that one will know the domain for a given use.) Thanks to Peter Kung.
} 
systematic ways; each meaning of 'must,' for instance, is related to a corresponding 'might' in a uniform way; ambiguous terms don't have such cross-meaning generalizations. ${ }^{12}$

Furthermore, we can combine senses for modal terms in a way not predicted by the ambiguity thesis. We can say, for instance,

Your theory is possible with respect to the laws of nature, but not with respect to the evidence.

Here 'possible' is used only once in a sentence conveying both epistemic and nonepistemic modality. The suggestion is a physically possible one (non-epistemic), but one known not to obtain (epistemic). That a single use can be extended to both senses strongly suggests that the word is not ambiguous between them. ${ }^{13}$ So the fact that 'possible' and 'necessary' sometimes express metaphysical modality, and sometimes do not, is not explained by an ambiguity in those terms.

According to the dominant view in formal semantics, modals are quantifiers over sets of worlds, where the relevant sets of worlds are determined by a function provided by the conversational context. ${ }^{14} \mathrm{We}$ can often force particular readings with adjectives like 'physically' or 'epistemically', or we can even relativize our modal claims more specifically with more explicit descriptions of modal bases, using phrases like "in view of what she knows," or "in view of what I read in the Times last week." There is a certain philosophical context in which the modal base comprises the set of all metaphysically possible worlds; we can trigger this context manually by affixing 'metaphysically' to our modal terms.

When we speak of 'modal epistemology,' we typically mean to be considering the epistemology of these rather particularly philosophical modal propositions. But these propositions are deeply and closely related to those we express with modal language in more quotidian contexts; they differ only in having different modal bases. They differ in subject matter rather than in form.

\section{§3. Quotidian Modals and the How Question}

So quotidian modals are closely connected to metaphysical modals. To ask whether $\mathrm{p}$ is metaphysically possible is to ask the same kind of question as whether $p$ is physically possible, or possible in some more restrictive sense provided by context. We now have

\footnotetext{
12 'Walk' and 'run' are each ambiguous between a kind of pedestrian locomotion and a baseball event. In the baseball sense, one can in certain circumstances generate a 'run' by 'walking'. But we have no temptation to carry the generalization into the locomotive sense.

${ }^{13}$ See Zwicky \& Sadock (1975).

${ }^{14}$ Kratzer (1977) is an important seminal work. Chapter 3 of Portner (2009) gives a helpful contemporary overview.
} 
available a sketch of an evolutionary approach to the Why question described at the start of $\S 2$.

Quotidian modals certainly have a strong prima facie claim to conferring significant survival advantages on our ancestors. I walked through a dangerous part of town alone at night, and you say to me:

$$
\text { You could have been mugged. }
$$

In typical contexts, you express not that it is metaphysically possible that I should have been mugged, but that among some nearer, restricted set of worlds there are some in which I was mugged. And it is not mysterious that we should have the cognitive ability to know propositions like this one; both developmentally and evolutionarily, we have faced good reason to develop the capacity for knowledge of such propositions as these. Or at least, this seems like an extremely plausible evolutionary story. It is of course an empirical question to what degree our capacity for quotidian modals was in fact an evolutionary adaptation for planning and better decision-making; there is no contradiction in the idea that it arose spontaneously and by coincidence in a way wholly unrelated to natural selection. If this is in fact so, then there is no substantive answer to the Why question for quotidian modals; perhaps then it'd be enough to observe that we have the capacity. Lucky us!

Whether by coincidence or (as seems to me much more plausible) by natural selection, it is relatively unmysterious that we have capacities for knowledge of quotidian modals. And these capacities, I suggest, should be general ones that equip us to evaluate modals generally. There is no prima facie reason we should expect the case of metaphysical modality to require different fundamental epistemic capacities for their evaluation. We have a general ability to evaluate, given a modal base, whether a necessity or a possibility claim holds of it. (I shall return later to the question of how we determine what to include in a modal base.) That is the sense in which quotidian modals illuminate the How question for metaphysical modality.

But there is another significant question that yet remains unanswered. Why is it that, in the context of philosophical discussions of modality, we work with the domain of metaphysically possible worlds, rather than some other more or less restrictive domain? If ordinary quotidian modals represent restricted quantification over a limited class of possibilities, what does the general, unrestricted modality include? It's clear enough that the physically possible is a restriction on the metaphysically possible. One might continue to suggest that the metaphysically possible is a subset of the conceptually or logically possible — and perhaps so on further into various logically impossible 'possibilities'. And crosscutting some or all of these might be the epistemically possible. Or one might somewhere draw the line, insisting that one has already identified all of the unrestricted possibilities.

But where to draw the line? Bealer (2002) draws the line at the metaphysically possible:

[S]ome people insist on distinguishing logical possibility and metaphysical possibility

Ichikawa 
and so are led to the following: $\mathrm{p}$ is logically possible iff $\mathrm{p}$ is merely consistent with the laws of logic (i.e., not ruled out by logic alone). This usage, however, invites confusion. There are many logically consistent sentences that express obvious impossibilities (e.g., 'Bachelors are necessarily women', 'Triangles are necessarily circles', 'Water contains no hydrogen'). If you buy into calling mere logical consistency a kind of possibility, why not keep going? For example: $p$ is 'sententially possible' iff $p$ is consistent with the laws of sentential logic. Then, since 'Everything is both $F$ and not $F$ ' is not ruled out by sentential logic (quantifier logic is what rules it out), would it be possible in some sense (i.e., sententially possible) that everything is both F and not F?! Certainly not my ear! $(78-79)$

Bealer is here too quick, for at least two reasons. ${ }^{15}$ First, the logical structure of the argument for drawing the line at metaphysical possibility is suspect. It follows a particular erroneous form of a slippery slope argument: if you permit X (which doesn't seem too bad), then what's to stop you from going on to permit Y (which seems terrible)? The difference in felt terribleness, if there is one, would provide just the needed traction between $\mathrm{X}$ and $\mathrm{Y}$ in order to avoid the slip. Remember that drawing the line at metaphysical possibility represents a substantive choice; one might try to draw it even more narrowly — at physical possibility, say.

Imagine a philosopher who refuses to countenance those 'metaphysical possibilities' which violate the laws of physics; he will insist that they're in no sense possible. Against someone like Bealer, who believes in such 'physically impossible possibilities', he might offer just the same retort: "if you buy into calling mere metaphysical consistency a kind of possibility, then why not keep going?" Bealer presumably thinks that there is good reason to countenance metaphysical possibility; but for all Bealer has said, it may well be that further conceptual or logical possibilities can be put to similar work.

The second reason to be concerned with Bealer's argument is that he makes an insufficient case for the undesirability of the bottom of his slippery slope. Bealer apparently finds the suggestion that there is a sense in which the sentence in question is possible implausible. He doesn't say why, but the invocation of how it strikes his ear suggests it may be based in a linguistic intuition; it just sounds terrible, perhaps, to say that there's a sense in which it is possible that everything is both $\mathrm{F}$ and not $\mathrm{F} .{ }^{16}$ But that there is some sense in which it is possible does not, of course, imply that it's a very interesting sense, or one that ordinary speakers are used to thinking about. Bealer ostends a notion of 'sentential possibility', abstracting away from any use to which thinking about it might be put. It shouldn't come as any surprise, then, that, so presented, we shouldn't have any interest in thinking about such 'possibilities'. That doesn't mean they're not there, ready for us to take them up if and when the course of inquiry demands it.

\footnotetext{
${ }^{15}$ See also Ichikawa \& Jarvis (2013) p. 48 for related discussion.

${ }^{16}$ Brian Weatherson points out, in personal communication, another objection to Bealer's particular example. The relevant sentence looks like it might well be metaphysically, let alone 'sententially', possible, on the assumption that there is a metaphysically possible world that contains nothing. If so, 'everything is both $\mathrm{F}$ and not $\mathrm{F}^{\prime}$ is (vacuously) true of that world.
} 
Remember again the philosopher who thinks of physical possibility the way Bealer feels about metaphysical possibility. He will respond just the same way Bealer does, in response to what is conventionally recognized as the physically impossible metaphysically possible. "It's just not possible in any sense for humans to travel faster than light." If you have introduced such metaphysical issues to undergraduate students, you've probably encountered people who respond this way at first.

Drawing the line at metaphysical possibility represents a substantive choice; one might try draw it even more narrowly - we've been imagining someone drawing it at physical possibility. Imagine a philosopher who refuses to countenance those 'metaphysical possibilities' which violate the laws of physics; he will insist that they're 'in no sense possible'. If there is reason to countenance metaphysical possibilities - and I agree with Bealer that there is - then presumably, we will justify it by reference to the useful work to which thinking about metaphysical modality can be put. It is to a considerable degree an open question, to what degree the class of metaphysically possible worlds is a theoretically important one-Ted Sider argues that the distinction is not metaphysically fundamenta ${ }^{17}$ - but if Kripke $(1971,1980)$ is right that metaphysical modality has central roles to play in discussion of identity, that might be good reason to treat metaphysical modality as significant at least to the extent that identity is.

In the same way, there is room to argue for or against the theoretical significance of further, metaphysically impossible, 'possibilities'. For example, Ichikawa \& Jarvis (2013) argue at length that we should accept a notion of 'rational possibilities' that outstrip the metaphysically possible. One reason we might need such possibilities is to model the rationality of a person in a Frege case: suppose that someone believes, on the basis of excellent evidence, that Hesperus is a planet, and also believes, on similarly strong (but misleading) evidence, that Phosphorus is not a planet. On our view in that book, invocation of rational possibilities - like the possibility that Hesperus is a planet, but Phosphorus is not - are necessary to explain the possible rationality of such a combination of attitudes. (ibid., pp. 61-66) This, even though there is no metaphysical possibility corresponding to this rational possibility. Whether or not we were right to invoke such possibilities need not be decided here: the point is that the idea is intelligible, and there are possible grounds for drawing the line in different places than at the boundaries of metaphysical possibility.

Why, in the philosophical contexts in which we do so, do we draw the line at the metaphysically possible? Timothy Williamson (2007) objects to a strategy much like mine by emphasizing this question, considering his own counterfactual-based strategy relevantly superior. Williamson writes:

Can metaphysical possibility be understood as the limiting case of such more restricted forms of possibility? Perhaps, but we would need some account of what demarcates the

\footnotetext{
${ }^{17}$ Sider (2011), pp. 266 et seq. However, note that Sider's claim, that metaphysical modality is not (totally) fundamental, is consistent with its being a relatively fundamental notion. Just as green is not fundamental, but is more fundamental than grue, so might metaphysical modality not be fundamental, but yet be rather fundamental - more so than other gerrymandered notions of modality.
} 
relevant forms of possibility from irrelevant ones, such as epistemic possibility. It also needs to be explained how, from the starting-point of ordinary thought, we manage to single out the limiting case, metaphysical modality. The advantage of counterfactual conditionals is that they allow us to single out the limiting case simply by putting a contradiction in the consequent; contradictions can be formed in any language with conjunction and negation. (178)

The relation between quotidian modality and metaphysical modality, Williamson suggests, is not so straightforward as automatically to dispel the mysteriousness of sui generis faculties for metaphysical modality. To say that knowledge of metaphysical modality is obtained via the exercise of our general faculty for modals is to leave an important question unanswered: why is it that we countenance the class of possibilities that we do, rather than some other one? Why don't we countenance further 'possibilities' that extend beyond the metaphysically possible (as we do in sentences like (1))? Why do we countenance possibilities as far out as we do, rather than considering some more or less restricted set of possibilities as the limiting case? There is nothing about our practice of quotidian modal reasoning, for example, that requires us to countenance faster-thanlight travel as 'possible', or denials of a posteriori identities as 'impossible' in the relevant metaphysical sense.

I agree that this question goes unanswered by an evolutionary approach to the Why question in terms of quotidian modals. However, I do not think we should be too bothered by this particular failure. For one thing, his own claim to the contrary notwithstanding, Williamson's favored approach fails to answer this question in just the same way. I argue that this is so in $\S 4$. In $\S 5$, I'll suggest why I think it's just fine to leave this question open at this stage.

\section{§4. Counterfactuals and Modality}

Williamson's preferred (2007) approach, following that of Hill (2006), emphasizes connections between metaphysical modality and counterfactuals. The capacity to evaluate counterfactual conditionals, like that for quotidian modals, has a strong prima facie claim to conferring an evolutionary advantage on a subject who has it. So it is no great mystery that we ended up with a capacity for counterfactual conditionals; the Hill/Williamson strategy is to understand our capacity for metaphysical modality as a natural side-effect of this ability.

In particular, both Hill and Williamson argue that claims of possibility and necessity are equivalent to certain counterfactuals. They prove several equivalences; I'll focus on these:

(NEC) $\square \mathrm{p} \equiv(\sim \mathrm{p} \square \rightarrow \perp)$

(POS) $\quad \forall \mathrm{p} \equiv \sim(\mathrm{p} \square \rightarrow \perp)^{18}$

\footnotetext{
${ }^{18}$ Williamson (2007), p. 157, my labels. For other similar formulations, see ibid. pp. 156-159 and Hill (2006), pp. 220-223.
} 
(Where $\perp$ stands for an arbitrary contradiction.)

There is a strong intuitive case for the truth of (NEC) and (POS). A counterfactual conditional A $\square \rightarrow \mathrm{B}$ is true just in case, for some relevant restricted class, all of the possibilities in which $\mathrm{A}$ are possibilities in which $\mathrm{B} .{ }^{19}$ For all of the possibilities in which A to be contradiction-possibilities just is for A to be impossible. Given these equivalences, Williamson suggests, a capacity for counterfactual conditionals will bring with it a capacity for metaphysical modality.

The derivation of these equivalences relies, as Williamson observes, critically on the assumption that counterfactual conditionals with impossible antecedents are vacuously true. ${ }^{20}$ This feature of Williamson's argument has been targeted by some philosophers sympathetic to nontrivial 'impossible worlds' ${ }^{21}$ As will emerge, my own criticism of the Hill/Williamson view is not unrelated to this strategy, although I am not interested in denying that (NEC) and (POS) are true.

Another challenge for the Hill/Williamson story—one pressed by Jenkins (2008) — is that it is difficult to see how it helps actually to explain modal knowledge, unless it's thought that modal truths are inferred from the corresponding counterfactuals. Notice, for instance, the lacuna in this description of the view from Hill:

\begin{abstract}
We may believe that it is metaphysically necessary that $2 \times 3=6$, but is this something that we know? Can we be said to know that it is metaphysically necessary that Lord Darnley and Mary Queen of Scots were the parents of James I? As I see it, it is plausible that we do in fact know such things to be true. Thus, if the theory of the metaphysical modalities I have recommended is right, then claims of metaphysical necessity are equivalent to generalized subjunctive conditionals. It seems reasonable to suppose that it is possible to know such conditionals, for they are concerned principally with questions of large-scale similarity, and it seems reasonable to suppose that we can know the answers to such questions, at least in some cases. (Hill 2006, p. 231)
\end{abstract}

Hill goes on to offer further reasons to think that knowledge of the relevant conditionals is possible, but does not remark on the possibility that subjects who have not recognized the equivalence might have this conditional knowledge, but fail to have the modal knowledge. As Jenkins points out in her response to Williamson, this is a significant omission, as epistemology is a hyperintensional matter. Note that this challenge does not arise for my approach, which emphasizes a general capacity for modals: the posited capacity just is a capacity for modal judgments.

\footnotetext{
${ }^{19}$ This statement is neutral between various semantic approaches to counterfactual conditionals. On David Lewis's (1973) account, for instance, the relevant class constitutes roughly the set of A-worlds that are most similar to actuality. We shall see below that alternate approaches to counterfactuals, such as those that treat them as restricted modals, also very directly yield this result. (If there are no A possibilities, then, trivially, all A possibilities are B, for any arbitrary B.)

${ }^{20}$ Or at least, never false; he observes (p. 176) that his main point can still be observed if such conditionals are treated as defective in a way that results in their having no truth value.

${ }^{21}$ Roca-Royes (2011). See also Jenkins (2008), p. 694.
} 
It seems to me that there is something importantly right about the Jenkins objection, although I also think that there is room for disagreement about just how damaging it is. Given the focus I have been suggesting on the Why question, an explanation for our capacity to deal with something equivalent to claims of metaphysical modality might be thought to resolve a significant degree of the question; the outstanding issue turns on the degree to which the unexplained capacity for drawing out the equivalence is a cognitive achievement demanding substantive epistemological explanation. I am genuinely unsure to what degree we should think this is so, so I will not press the Jenkins objection further. I consider it to be somewhere between a weak and a strong reason to be dissatisfied with the Hill/Williamson line.

My focus will be on a different challenge. The point I want to emphasize is that the Hill/Williamson line is also susceptible to the challenge Williamson himself presses for the quotidian modals approach.

Ordinary counterfactuals, like ordinary modals generally, are context-sensitive. ${ }^{22}$ For instance, it is widely recognized that in different contexts, different features of actuality are weighted more heavily with respect to comparisons of similarity. ${ }^{23}$ But such weighting of respects of similarity does not exhaust the context-sensitivity of counterfactuals. According to the dominant view in semantics, counterfactuals are restricted modals; like modals generally, they take a context-sensitive modal base. ${ }^{24}$ When more possibilities are considered as live possibilities - when there is less in the common ground - counterfactual sentences express stronger propositions. Consider this counterfactual:

If this glass were to fall, it would break.

In ordinary contexts, we ignore certain distant possibilities that would, if actualized, sever the connection between falling and breaking. Here, it is presupposed that no one will reach out of a window and catch the glass on the way down. Of all the possibilities in the modal base, only ones in which the glass breaks are among those in which it falls. So in ordinary contexts, (9) is true. But in some extraordinary contexts, we countenance more possibilities as relevant. If we are talking about the surprising possibilities in which people reach out of their windows to catch the glass, considering them to be, though distant, ones that are consistent with the conversational background, then (9) would express a falsehood, since, were the glass to fall, it might well be caught on the way down. ${ }^{25}$

\footnotetext{
${ }^{22}$ Williamson (pp. 173-74) mentions this widespread view without disputing it; he dismisses some objections to his view deriving from context-sensitive counterfactual conditionals, but does not consider the one I will press.

${ }^{23}$ Cf. the 'Caesar in Korea' counterfactuals; see Lewis (1986a), p. 34.

${ }^{24}$ Kratzer (1986). See also Ichikawa (2011).

${ }^{25}$ Those attracted to conditional excluded middle, of course, will disagree. I will not go into the arguments
}

Ichikawa 
The counterfactual conditional is understood as a restricted modal; (9) is interpreted as (Must:fall)(break). The modal base for the counterfactual, like modal bases for bare modals, is context-sensitive.

So there is an intimate connection between modals and counterfactual conditionals; the latter are a particular restricted kind of the former. It is trivial that Williamson's equivalences follow from this treatment of counterfactual conditionals. ${ }^{26}$ So the relevant counterfactuals do turn out, on the orthodox semantics, to be logically equivalent to the claims of possibility and necessity. Williamson is, to that extent, correct.

But — and here is the problem - the bare modals and the counterfactual conditionals each take context-sensitive modal bases. The ' $\square$ ' and ' $\checkmark$ ' are each relativized, in a context, to a given modal base; as, indeed, is each ' $\square \rightarrow$ '. Williamson has not shown that there is anything special about the particular context that provides the set of metaphysical possibilities. Quotidian engagement with counterfactuals doesn't tell us which modal bases to work with. The Hill/Williamson account leaves open the very same questions that that mine does.

Consider an example.

I'm a human being, with ordinary physical capacities. In particular, I can't fly home from work today. I could bicycle home, or take the bus, but I can't fly home from work today. That's a nice modal, true in its quotidian context:

$$
\square \sim(J o n a t h a n \text { flies home from work today) }
$$

When we say (10), there are certain distant scenarios that we ignore. If we're feeling fanciful, we may expand the common ground to open up some such possibilities; we might then end up in a context in which I could say, "I could fly home in a helicopter today," or even, if we were feeling more fanciful still, "I could sprout wings and fly home by my own power today." In such contexts, (10) is false. But in its natural context, (10) is true.

But notice what happens when we evaluate the counterfactuals that I said to be equivalent to these bare modals. Consider again a down-to-earth, unfanciful context in which (10) is true. What about this counterfactual?

If Jonathan were to fly home today, then grass would be both green and not green.

for and against conditional excluded middle here-see Williams (2010). I assume, with semantic orthodoxy and against Williams, that conditional excluded middle is false.

${ }^{26}$ Consider (NEC) $\square \mathrm{p} \equiv(\sim \mathrm{p} \square \rightarrow \perp)$. The right-hand side is understood as $(\square: \sim \mathrm{p})(\perp)$-all not-p worlds are contradiction worlds; i.e., there are no not-p worlds. 
This counterfactual is not plausible; there wouldn't be any true contradictions, regardless of whether I were to fly home today. But given (NEC), (10) and (11) are provably equivalent.

What has gone wrong? Pairs of sentences like (10) and (11), though truth-conditionally equivalent in every context, may have divergent effects upon the conversational score, such that the utterance of (10) will result in one context in which it (and the unuttered (11)) is true, while the utterance of (11) will result in another context in which it (and the unuttered (10)) is false). This is likely in this particular case, because we tend to shift contextual parameters to accommodate utterances as nonvacuous.

Consider an example with ordinary quantifiers. You and I are hosting a barbeque. You say:

$$
\text { Everyone has been fed. }
$$

The domain for your 'everyone' is a restricted one. You're excluding, for instance, Aunt Joan, who is dieting, as well as the many people who were not invited to our barbeque. Plausibly, you speak truly, because everybody who came to the barbeque, expecting to be fed - everybody in the domain — has been fed.

Now suppose I, with a perverse fondness of linguistic games, say:

$$
\text { Everyone who hasn't been fed has been fed. }
$$

I will most naturally be interpreted as saying something false — indeed, as saying something ridiculously false. But of course, (12) entails (13) in every context. Holding the domain of people fixed, if everyone in that domain was fed, then everyone in that domain who had any feature at all was fed. In particular, everyone in that domain who wasn't fed was fed. There was nobody like that, so (13), so evaluated, is vacuously true. But in general, we don't like to interpret sentences as vacuously true if we don't have to. So if (13) is uttered, we naturally accommodate the presupposition that there are some people who haven't been fed, expanding the domain, perhaps to include Aunt Joan or some strangers. In its new domain, (13) is false, rather than vacuously true.

Exactly the same thing happens with (10) and (11). When I say I can't fly home, I mean that, of a certain set of worlds, none of them are ones in which I fly home. If I say that, were I to fly home, such and such would be the case, I say, of a certain set of worlds, that all of the ones in which I fly home are ones in which such and such is the case. Even if we were previously in a context in which there were no flying-home worlds in the modal base, when I utter (11), we will typically shift to one in which there are some, in order to accommodate me as speaking nonvacuously.

This accommodation is not mandatory. Suppose I start talking about what it'd be like if I were to fly home today. You may accommodate me by allowing a modal base that includes flying-home worlds. But you might instead refuse to countenance such 
possibilities. There are a few ways you might do this. One rather direct way would be baldly to assert that I couldn't fly home, thus signaling your refusal to shift with me into a modal base that includes flying worlds. Or you could make the same point less directly by saying something like: "if you flew home, I'd eat my hat" or "it'd be the case that p \& $\sim$ p". That is, you might say something tantamount to, all of the possibilities in which I fly home are not possibilities at all.

To summarize: sentences expressing bare necessity are equivalent to sentences vacuously expressing certain counterfactuals, in all contexts. But often, those latter are accommodated via a shift in conversational context to render the counterfactuals in question nonvacuous. A conversational participant may be more or less cooperative in so accommodating.

We're left, then, wanting to ask the counterfactuals approach the same question Williamson emphasized for the quotidian modals approach: why do we refuse to expand the domain, accommodating the relevant counterfactuals, at the set of metaphysical possibilities, rather than somewhere else? There is nothing obviously privileged about stopping here; the domain might be extended in either direction. We might, for instance, suppose various metaphysical impossibilities without inferring any sort of explosion: if I were a whale, I would have a tail, but not: if I were a whale, I would climb trees. Or we might refuse to countenance any physical impossibilities, declining to accommodate the antecedents of conditionals like 'if humans could fly, then $\mathrm{p} \& \sim \mathrm{p}$ ', rendering them vacuously true. Or we might do the same for any other of the myriad possible restricted notions of possibility. Williamson's way of distinguishing the distinctively metaphysically possible relies on an as-yet-unexplained tendency for us to be just openminded enough, but no more.

One might object that it isn't necessary to explain why we stop where we do; it's enough to observe that we do so. This does seem to me a good objection, but it is not an available defense for Williamson; his complaint against the quotidian modals approach was precisely that it fails to explain that which his own view also fails to explain. My response is that his own approach exhibits just the same shortcoming that he pointed out for the quotidian modals approach: it fails to provide "some account of what demarcates the relevant forms of possibility from irrelevant ones" and to explain "how, from the starting-point of ordinary thought, we manage to single out the limiting case, metaphysical modality."

Recall the advantage that Williamson claimed for his own approach: "[t]he advantage of counterfactual conditionals is that they allow us to single out the limiting case simply by putting a contradiction in the consequent. ${ }^{, 27}$ But contradictions in the consequent do not serve to identify the limiting case; they merely serve to flag that we have reached our limit. There is nothing in the semantics of counterfactual conditionals that requires us to draw the line at metaphysical possibilities, rather than somewhere else. And Williamson

\footnotetext{
${ }^{27}$ Williamson (2007), p. 178.
} 
hasn't shown us anything about the ordinary practice of counterfactuals that demands the line be drawn just there.

\section{§5. The Way Metaphysical Modality is Sui Generis}

So the Hill/Williamson treatment cannot answer Williamson's challenge any more than mine can. (We have seen that his also faces additional challenges.) Where now do we stand?

The deficiency of the quotidian modals approach is not total. It does offer an avenue for explanation of why it is that we should have the capacity to think modally; what it lacks is an explanation for our thinking modally with respect to the particular domain of the metaphysically possible worlds. That is to say, what it lacks is an explanation for our engaging with the particular subject matter that we do. It does not explain why we think about the set of metaphysical possibilities.

The evolutionary approach to the Why question in terms of quotidian modals does not answer this question. But the question is not a deeply mysterious one. In general, when seeking an explanation for our thinking about the particular subject matters that we do, one needn't look to evolutionary history; one might just as well look to our particular individual developmental histories. The reason we think about the set of metaphysical possibilities is that we're trained to do so; plausibly, this is because the set has interesting properties that have emerged in our philosophical investigations. To take one prominent example, questions about metaphysical possibility have proven to be extremely fruitful for theorizing about identity. Cf. Kripke $(1971,1980)$.

As the remarks of the previous section show, we face no great pressure to suppose that people often use beliefs or knowledge about distinctively metaphysical possibilities in their quotidian lives. Our modals choose from a variety of bases, depending on the needs of the conversation. Usually, they expand as far as necessary in order to accommodate the various utterances we encounter; only occasionally do we refuse to accommodate - and when we do, we may, and often do, so refuse at a point other than that which demarks the boundaries of the metaphysically possible. We're trained to be sensitive to this particular line in our philosophy courses. ${ }^{28}$

\footnotetext{
${ }^{28}$ Or so it seems to me. Of course, this is an empirical question; one might discover that humans become sensitive to this distinction in some other way. Shaun Nichols, in yet-unpublished work, is investigating young children to see whether they treat the category of metaphysical modality in a privileged way. One can, perhaps, get traction on this question by asking children to distinguish, of various events that are impossible in some more restricted sense, which might be possible 'by magic,' and which not even magic could achieve. Such is (a simplified version of) Nichols's strategy; I look forward with interest to engaging his results. It is also possible, as an anonymous referee pointed out to me, that particular contingencies of our cultural backgrounds could end up playing a role in influencing our selection of this category of possibility. This is of course a deeply empirical question.
} 
Does this represent a concession to the kind of anti-realism I was motivated to avoid in the introductory sections? ${ }^{29}$ Not necessarily - it all depends on whether the distinction we're trained to respect is a genuinely theoretically interesting one. ${ }^{30}$ For the reasons mentioned above having to do with identity, it seems to me rather plausible that they are; but detailed investigation here would take us too far afield. I have not refuted the antirealist suggestion that the only reason one might be interested in metaphysical modality is to satisfy the perverse and idiosyncratic interests of philosophers, but I have given a framework for an epistemology that does not require it.

So there is a sense in which metaphysical modality is sui generis. But it need require no sui generis faculty; it merely engages a sui generis subject matter. And there is no great mystery why we should choose to think about any particular subject matter. So the evolutionary approach in terms of quotidian modals does show what needed showing: that it is unmysterious why we should have the relevant faculty, even on the assumption that metaphysical modality comprises an objective realm. ${ }^{31}$

\section{Bibliography}

Bealer, G. (1992). The Incoherence of Empiricism, Aristotelian Society Supplementary Volume 66: 99-137.

Bealer, G. (2002). Modal Epistemology and Rationalism. In T. S. Gendler, John (Ed.), Conceivability and Possibility (pp. 71-125). New York: Oxford University Press.

BonJour, L. (1985). The structure of empirical knowledge. Cambridge, Mass.: Harvard University Press.

Cappelen, H. (2012). Philosophy Without Intuitions. Oxford: Oxford University Press.

\footnotetext{
${ }^{29}$ Thanks to Peter Kung for raising this question.

${ }^{30}$ It isn't trivial even to articulate what the realism in question comes to; that the truths of metaphysical modality are objective facts is insufficient for the more interesting forms of realism. Consider what might be a clear case of an anti-realist modality: fashion modals. (Thanks to Peter Kung for the suggestion.) We're told that "one can't wear white after Labor Day"- this means that, among a certain set of worlds (the worlds where one abides by the fashion rules), there are none where one wears white after Labor day. It is of course an objective fact whether or not any of those worlds are ones in which one wears that then; but the rules of fashion are paradigmatically arbitrary. We should be anti-realists there if anywhere.

Presumably the way to carve the realist distinction we want, then, involves whether the modal base we use (or the properties of worlds we use to identify the modal base) is a (reasonably) natural one. See Sider (2011), ch. 4.

${ }^{31}$ Thanks to Derek Ball, Yuri Cath, Torfinn Huvenes, Carrie Ichikawa Jenkins, Josh Schechter, Stewart Shapiro, Margot Strohminger, and Timothy Williamson for discussion of early drafts of this paper and related issues. Special thanks to Peter Kung and an anonymous referee for detailed comments on a latestage draft. Versions of this paper were presented at the "Knowledge through Imagination" conference in Claremont, CA, and a workshop on "Metaphysical Knowledge" in Paris; thanks to helpful audiences at both events for discussion. Some of the research for this paper was supported by the Arts and Humanities Research Council as part of Arché's "Intuitions and Methodology" project.
} 
Chalmers, D. (2002). Does Conceivability Entail Possibility. In T. a. H. Gendler, John (Ed.), Conceivability and Possibility (pp. 145-200). New York: Oxford University Press.

Gendler, T., \& Hawthorne, J. (2002). Introduction. In T. Gendler \& J. Hawthorne (Eds.), Conceivability and Possibility (pp. 1-70). New York: Oxford University Press.

Hill, C. S. Modality, Modal Epistemology, and the Metaphysics of Consciousness. In S. Nichols (ed.), The Architecture of the Imagination: New Essays on Pretense, Possibility, and Fiction (pp. 205-235). Oxford: Oxford University Press.

Ichikawa, J. J. (2011). Quantifiers, Knowledge, and Counterfactuals. Philosophy and Phenomenological Research 82(2): 287-313.

Ichikawa, J. J., \& Jarvis, B. W. (2012). Rational Imagination and Modal Knowledge. Nous 46(1), 127-158.

Ichikawa, J. J., \& Jarvis, B. W. (2013). The Rules of Thought. Oxford: Oxford University Press.

Jenkins, C. S. (2008). Modal Knowledge, Counterfactual Knowledge and the Role of Experience. The Philosophical Quarterly, 58(233), 693-701.

Kratzer, A. (1977). What Must and Can Must and Can Mean. Linguistics and Philosophy, $1,337-355$.

Kratzer, A. (1981). The Notional Category of Modality. In Words, Worlds, and Contexts: New Approaches in Word Semantics, H. J. Eikmeyer and H. Rieser (eds.), 38-74. Berlin/New York: Mouton de Gruyter

Kratzer, A. (1986). Conditionals. Chicago Linguistics Society, 22, 1-15.

Kripke, S. A. (1971). Identity and Necessity. In M. K. Munitz (Ed.), Identity and Individuation (pp. 135-164). New York: New York University Press.

Kripke, S. A. (1980). Naming and necessity. Cambridge, Mass.: Harvard Univrsity Press.

Lehrer, K. (2000). Theory of knowledge, Dimensions of philosophy series

Lewis, D. K. (1973). Counterfactuals. Cambridge,: Harvard University Press.

Lewis, D. K. (1986a). Counterfactual Dependence and Time's Arrow Philosophical Papers, Volume 2 (pp. 32-66). New York: Oxford University Press.

Lewis, D. K. (1986b). On the plurality of worlds. Oxford: Basil Blackwell. 
O'Leary-Hawthorne, J. (1996). The Epistemology of Possibility: A Guided Tour. Philosophical Studies, 84, 183-202.

Portner, P. (2009). Modality. Oxford: Oxford University Press.

Roca-Royes, S. (2011). Modal Knowledge and Counterfactual Knowledge. Logique et Analyse, 54(216), pp. 537-552.

Schechter, J. (2010). The Reliability Challenge and the Epistemology of Logic. Philosophical Perspectives, 24, Epistemology, 437-464.

Sider, T. (2011). Writing the book of the world. Oxford and New York: Oxford University Press.

Sosa, E. (2007). A virtue epistemology. Oxford and New York: Oxford University Press.

van Inwagen, P. (1998). Modal Epistemology. Philosophical Studies, 92(1), 67-84.

Williams, J. R. G. (2010). Defending Conditional Excluded middle. Nous, Online Early.

Williamson, T. (2007). The philosophy of philosophy. Malden, Mass.; Oxford: Blackwell Publishing.

Yablo, S. (1993). Is Conceivability a Guide to Possibility? Philosophy and Phenomenological Research, 53(1), 1-42.

Zwicky, A. M., \& Sadock, J. M. (1975). Ambiguity Tests and How to Fail Them. Syntax and Semantics, 4, 1-36. 